\title{
The Enduring Value of Research in Medical Education
}

\author{
Juliana Bonilla-Velez, ${ }^{1,2}$ Mariah Small, ${ }^{1}$ Raul Urrutia, ${ }^{3}$ Gwen Lomberk. ${ }^{4}$
}

\begin{abstract}
Evidence-based medicine (EBM) relies on scientific data to guide diagnosis and treatment and is recognized as the current paradigm in medicine. Accordingly, every current and future physician should be knowledgeable about its principles and methodologies. Embracing research and EBM is essential to modern clinical practice; however, trainees and physicians still struggle with the value of research-related courses and knowledge on epidemiology and research methodology is often poor. In this article we provide a cogent discussion of the importance of research as an indispensable discipline in medical education through a detailed analysis of the literature. We review the evolution of medicine towards EBM and discuss the myriad of benefits that research has on medical careers, leadership roles, mentoring relationships, social networking, and personal growth and development. Participation in research contributes to medicine, public health, and society while simultaneously allowing the achievement of a high level of personal satisfaction.
\end{abstract}

Keywords: Education, Medical; Students, Medical; Research. (Source: MeSH-NLM).

\section{Introduction}

The publication from the Evidence-Based Medicine Working Group in 1992 defined evidence-based medicine (EBM) as the new paradigm for medical practice.1 Under this paradigm, the decisions regarding diagnosis and treatment are no longer solely dependent on prior clinical experience, but now include an additional factor: evidence. As a result, physicians have needed additional skills to understand and apply published information in their practices and to help produce the continuous flow of research supporting this system. Despite the fact that EBM has been the model of medical practice for the past two decades, knowledge of research methodology and criteria for the critical evaluation of reported evidence often remains poor among students worldwide.2-5 Clinical investigators, who are essential for the final generation of evidence needed to maintain the practice, have been called an "endangered species" 6,7 In this article, we discuss many reasons that support the value of research as a foundational discipline in medical education. We also emphasize how physicians-in-training can benefit from this experience and gain skills that can serve as a valuable tool for their future practices. Therefore, we are optimistic that the reader will find this article both informative and inspiring. A practical approach of how to apply this knowledge into practice is listed in Table 1.

Medicine: A Paradigm Shift through the Ages Western medicine has evolved parallel to social and scientific advancements as "a varied and changing social and cultural system", ${ }^{8}$ which has led the field toward the practice of EBM. After prehistoric humans believed in using magic to heal, Greeks introduced rational explanations for medical phenomena and described illness as a study of its signs and symptoms resulting in the development of "clinical observation", 9 a method

Editor: Ahmed Radwan.

Submission: 2016-07-21

Acceptance: 2017-06-10

Process: Peer-review

${ }^{1}$ Dept of Otolaryngology - Head and Neck Surgery, University of Arkansas for Medical Sciences, USA

${ }^{2}$ Universidad del Valle, Cali, Valle del Cauca, Colombia.

${ }^{3}$ Professor, Departments of Biochemistry and Molecular Biology, Biophysics and Medicine, Mayo Clinic College of Medicine, Rochester, MN, USA

${ }^{4}$ Assistant Professor, Department of Medicine, Mayo Clinic College of Medicine, Rochester, MN, USA

Correspondence:

Gwen Lomberk

Email: lomberk.gwen@mayo.edu
Table 1. Framework of topics that will be covered in this review.

\begin{tabular}{|c|c|c|c|c|}
\hline Introduction & $\begin{array}{c}\text { The relevance of research in the } \\
\text { current paradigm of Evidence- } \\
\text { Based Medicine. }\end{array}$ \\
\hline $\begin{array}{c}\text { Medicine: A Paradigm Shift through } \\
\text { the Ages }\end{array}$ & $\begin{array}{l}\text { How medicine has evolved to its } \\
\text { current paradigm of EBM and the } \\
\text { role of research in this setting. }\end{array}$ \\
\hline $\begin{array}{c}\text { Relevance of Research for } \\
\text { Physicians in Training }\end{array}$ & $\begin{array}{l}\text { The importance of research and } \\
\text { EBM for medical students at this } \\
\text { stage of training. }\end{array}$ \\
\hline Implications for Future Career Plans & $\begin{array}{l}\text { The importance of research for } \\
\text { medical students future career } \\
\text { plans. }\end{array}$ \\
\hline $\begin{array}{c}\text { Research as a Catalyst for } \\
\text { Leadership and Social Networking }\end{array}$ & $\begin{array}{l}\text { Research as an opportunity } \\
\text { to interact with leaders in the } \\
\text { field and to develop mentoring } \\
\text { relationships with individuals. }\end{array}$ \\
\hline $\begin{array}{c}\text { Elevating Medical Students to the } \\
\text { Demand of Current Medicine }\end{array}$ & $\begin{array}{l}\text { How participation in research } \\
\text { permits the progression of } \\
\text { medicine by helping translate } \\
\text { knowledge from bench to bedside. }\end{array}$ \\
Concluding Remarks & $\begin{array}{l}\text { How to become the future of } \\
\text { medicine. }\end{array}$
\end{tabular}

still used today. The scientific spirit of the Greeks was rediscovered during the Renaissance and the Enlightenment when medicine evolved from describing generalizations to solving specific questions through experiments, thus advancing knowledge through the scientific method. 9 The knowledge generated by the Europeans was later spread through colonialism during the Industrial Revolution. Advances in Western medicine were then being generated from multiple areas around the world. At the forefront were American scientists and inventors who were propelled by their ideologies of freedom of expression and pursuit of knowledge. Advances in communication that followed the track of the Industrial Revolution led to the construction of a 
unified scientific knowledge worldwide. ${ }^{9}$

In the nineteenth century, after Flexner's analysis of medical education, medicine progressively separated from pure empiricism and became part of modern science with scientific methodology. ${ }^{10}$ With the progressive introduction of medical research into clinical practice, "intuition, unsystematic clinical experience, and pathophysiological rationale"1 were no longer enough, and systematic evidence was required to determine standards of care. As a result, EBM became the new paradigm of medicine.' Epidemiology and biostatistics emerged as the fundamental basic sciences supporting clinical research, while the scope of research focused on studying new treatment strategies and optimal care." This shaped the clinical decision-making process and imposed new challenges by requiring every physician to understand the basics of the scientific method and demanding constant research to fuel advances in their field. As a result of the wide recognition of EBM, the Association of American Medical Colleges (AAMC) called for all medical schools to incorporate mandatory education on clinical and translational research in 2006. ${ }^{11}$

History illustrates how the practice of medicine evolved with the development of science and culture. This progress was driven by scientists and natural philosophers (researchers), and this concept remains strong today. By combining descriptive, experimental, and translational methods, research became a significant part of medical practice; thereby illustrating how medicine is an "ever evolving science based on research". ${ }^{12}$

\section{Relevance of Research for Physicians in Tra- ining}

If the practice of medicine is based on EBM, what does this mean for current and future practitioners? That the language in which medicine is currently written is no longer prose, but scientific in nature. By definition, EBM is "the conscientious, explicit, and judicious use of the most current and best evidence in making decisions about the care of individual patients," and its "practice means integrating individual clinical expertise with the best available external evidence from systematic research". ${ }^{13}$ Regulatory organizations usually consider that understanding scientific principles and EBM is necessary throughout medical training.

The Flexner report was pivotal in restructuring medical education in America and describes medicine as a discipline that follows the laws of biology and therefore one that can be studied using the scientific method. ${ }^{10,14}$ Flexner highlighted the importance of self-education and learning by doing. By mastering research as a critical tool for developing new knowledge, medical trainees would become critical thinkers who learned to evaluate information for themselves. ${ }^{10,14}$ These principles remain current as exemplified by the report from The World Federation for Medical Education (WFME) Task Force on Designing International Standards in Basic Medical Education. This report requires medical schools to "teach the principles of scientific and evidence-based medicine, and analytical and critical thinking throughout the curriculum"15 and now it is widely accepted that medical graduates should understand the methodology and applications of rigorous research. ${ }^{16}$ Evidence-based medicine permeates most categories of competencies required by the
Accreditation Council for Graduate Medical Education (ACGME) for completion of a residency program, including patient care, medical education, and practice-based learning and improvement. ${ }^{17}$ Acquiring these skills is fundamentally facilitated by involvement in research.

Consequently, the ideal moment to grasp the fundamentals of EBM and research methodology occurs during medical school, and some even advocate for initiation during undergraduate studies. ${ }^{18}$ Overwhelmed by curricular requirements, sleep deprivation, and financial concerns, students may perceive initiatives toward understanding research methodology and applying findings to clinical care as an additional stressor to their training. Therefore, students have reported lack of interest towards research, misconceptions of what research entails, or the perception that their time invested will not be reflected by the appropriate recognition. ${ }^{19-23}$ Although epidemiology and biostatistics are viewed as relevant knowledge, they lose importance as students progress through medical school, and disagreement on having research as part of their curriculum has been reported. ${ }^{18,19,24}$ Furthermore, student involvement in research varies widely among institutions and countries. The proportion of students from a given medical school who participate in research has been reported as $25 \%$ in New Zealand, $57 \%$ in Canada, and $54.6 \%$ with a $35 \%$ publication rate in Colombia (personal communication, Program of Medicine and Surgery, Universidad del Valle, September 26,2013$).{ }^{21,24}$ Some schools have adopted specific programs designed to promote research among students with encouraging results. Historical data from Stanford reports a $95 \%$ participation in research with a $75 \%$ publication rate after research had been encouraged among students. 25 Similar research programs during medical school have been implemented at other institutions with positive results. ${ }^{22,26-36}$ This information suggests that despite some motivation by students to participate in research, further strategies are needed for medical schools worldwide to promote the participation of students in research, completion of their projects, and divulgation among the medical and scientific communities.

Despite the differences in the proportion of medical students who participate in research, those involved in this activity recognize the numerous skills acquired in the process. ${ }^{26}$ Research participation aids in the development of investigational and analytical thinking, critical reading and writing abilities, organization and time management expertise, and communication skills. ${ }^{11,34,37,38}$ Research also teaches discipline and responsibility and improves competences required in all aspects of training, such as public speaking and literature searches and evaluation. ${ }^{37,39}$ Progressing through the steps in research and publication in a mentored setting facilitates the continuous practice and improvement of the ability to formulate hypotheses, conduct literature searches, understand research techniques, collect data, and critically evaluate the literature. All are practices that teach students to stay current and even advance science and medicine. ${ }^{22,31,38,40-42}$ These experiences provide skills incorporated in the student's armamentarium, whether they decide to pursue a career as a community-based clinician or in academic medicine. ${ }^{27}$

Similarly, research broadens a student's perspective towards medicine and its practice while teaching life-long lessons. By 
Table 2. Translation to Practice: Suggested applications of the information provided to your medical student life.

\section{Learning about evidence-based medicine allows you to start applying these principles from the beginning of your clinical experience, at the ideal time of your training.}

Early participation in research provides a wide variety of skills that will be beneficial throughout your training and professional life.

Understanding research methodology, statistics and analysis allows improvement in data interpretation and application of an evidence-based approach to clinical practice.

The development of research skills fosters greater personal growth and independence.

Participation in research promotes critical thinking, improvement in writing skills, public speaking, self-motivation and problem solving.

The balance of research with school obligations promotes time-management and punctuality.

Research experience will make you a more competitive and successful applicant whether this is for grant applications/obtaining funding as well as residency, fellowship and job applications.

Early involvement equips medical students with research skills needed in residency.

By partnering with faculty in projects you will gain mentors that will support you the rest of your life.

You can learn to have a team approach to medicine by seeing the collaborative efforts between departments.

The review of one's own work teaches the importance of identifying areas of improvement.

Familiarity with research objectives encourages the critical analysis of established practices.

Understanding study design and statistics prepares you for similar topics tested on the United States Medical Licensing Examination (USMLE) exams.

You can participate in local, regional or national research student organizations or journals to strengthen your own skill development as well as start networking.

Cooperation in research efforts prepares for similar roles in professional organizations.

The time spent exploring topics in depth aids in determining if a specialty is of interest to you.

understanding general principles in basic and clinical research, medical students can be more apt to integrate basic and clinical sciences during medical school, a skill that has been shown to contribute to successful learning. ${ }^{36}$ Some suggest that "physicians who think scientifically or critically provide the best patient care" ${ }^{\prime 3}$, and this way of thinking can also achieve a better understanding of the rapid changes in science, technology, and clinical practice. ${ }^{40}$ Participation in research also allows exploration of specialties to facilitate evaluation of interest in future training and empowers students to creatively face problems, propose multiple solutions, and assess the implications of published discoveries. ${ }^{44}$ These are all essential skills for effective clinical practice. Knowledge of research also facilitates interaction with patients when explaining implications from translational and clinical research to their care and when discussing enrollment in clinical trials. ${ }^{45}$ Lastly, these skills also will be applicable to everyday life. ${ }^{37}$ Research demands one to think for oneself, an extremely important quality for understanding scientific knowledge, EBM, and clinical practice. Medical students have recognized the benefits of research training for their current and future career, with up to $95 \%$ of students rating these experiences positively and reporting significant personal satisfaction. . $^{2,31,40-42,46-48}$ Thus comprehension and practice of research principles should be a priority during medical school.

\section{Implications for Future Career Plans}

Participation in research can impact student career choices by influencing their decision to become a physician-scientist or to practice in an academic center. ${ }^{31,33,40,41,43,49-52}$ Eighty-five percent of students who performed a research project as man- datory for graduation reported that the experience impacted their careers. ${ }^{31}$ Furthermore, students who are involved in structured training programs, such as the National Institute of Health (NIH)-sponsored Medical Student Research Fellowship programs (MSRFs), or many other school-based or peer-based programs have shown an increased appeal for academic medicine and have greater involvement in further research projects after the experience. ${ }^{16,18,33,38,50-53}$ This supports the idea that an early introduction to research fosters future career decisio ns. ${ }^{16,27-29,33,36,43,46,49,54-56}$

In addition to influencing the decision-making process, the experience and publications can help in advancing a medical career and facilitate a successful transition into the highly competitive field of academic medicine. ${ }^{22}$ Data from the Program in Clinical Effectiveness (PCE) at Harvard School of Public Health showed that graduates enrolled because research training was needed to advance their careers ( $66 \%)$, and a young age at the time of enrollment (less than 40 years) correlated significantly with receiving NIH grant funding (perceived as an indicator of a successful research career). ${ }^{57}$ Requiring research in medical school has shown to significantly increase publication productivity during and after training. ${ }^{39}$ In fact, those students who performed research were considered more competitive candidates for future training or job applications. ${ }^{25,31,32,39,44,58}$ Furthermore, participation of under-represented minorities in research has been shown to result in a more diverse workforce in academic centers, contributing to the improvement of teaching, patient care, and research. ${ }^{59}$ Individuals involved in research at earlier stages can be more successful as clinical investigators or physician scientists. Thus, we believe that implementing effective 
strategies to resonate this message to medical students worldwide is essential.

For most medical students, the next step in their careers will be applications to residency, for which experience in research may offer some additional endorsement. There are many factors that comprise a residency application, such as grades and rank for preclinical and clinical courses during medical school, the Medical Student Performance Evaluation (MSPE), United States Medical Licensing Examination (USMLE) Step 1 and Step 2 scores, letters of recommendation, Alpha Omega Alpha (AOA) membership, medical school reputation, awards, research experience, and publications. ${ }^{60}$ Interestingly, although research experience was ranked low in the selection criteria when all specialties were considered together, the most competitive specialties ranked research experience highly. ${ }^{60}$ Participants with one or more peer-reviewed publications received a significantly greater number of interview invitations than those without one ( $p<0.001) .{ }^{61}$ Accordingly, research experience with successful publication is a desirable quality for applicants. Participation in research is valued because of the overall strengths it instills within the applicant. Therefore, admission committees should be viewed as another source of mentorship, emphasizing the role of research in improving medical practice and professional satisfaction.

\section{Research as a Catalyst for Leadership and So- cial Networking}

With participation in research, medical students can interact with some of the most influential people in their fields, learn directly from those leading the waves of knowledge, and set the standards of care. The time spent with these leaders can be a unique opportunity to gain appreciation of science and to learn to question facts. In other words, this time provides an opportunity to learn how to look at the world and how to study it more efficiently. These leaders can also share their passion for research, which is an invaluable experience in and of itself. Mentors can boost the student's career by sharing their knowledge, offering professional advice, and providing support through many other personal interactions. Data suggests that up to $73 \%$ of medical students involved in a research project reported developing a relationship that optimized their research experience and went beyond project advising and mentoring, which has been shown to be crucial for pursuing a successful and satisfying academic career. ${ }^{22,31,41,49,55}$ This prolonged exposure is mutually beneficial, creating a positive relationship and facilitating better counsel and support for future career plans.

Through interaction with mentors, other principal investigators, scientists, post-graduate students, and peers, medical students can be inspired to do great things themselves, including participation in more research projects, leadership activities in scientific communities, organization of scientific meetings, and involvement in editorial activities, among many others. ${ }^{62,63}$ These activities are often channeled by scientific associations empowered by medical students at local, national, and international levels. The first author's personal experience in the Scientific Association of Medical Students of the Universidad del Valle (ACEMVAL), the Colombian Association of Medical Students' Scientific Societies (ASCEMCOL), the Latin American Federation of Medical Student Scientific Societies (FELSOCEM), the
International Federation of Medical Students' Association (IFM$S A$ ), and the International Journal of Medical Students (IJMS) has drastically influenced her way of thinking and her career, motivating her to write this article. Such activities serve as catalysts for passionate students who are bursting with ideas and motivation to contribute to society. This opportunity brings together people from different institutions, cities, countries, and continents and harnesses the diverse intellectual power. For example, the International Journal of Medical Students (IJMS), created by an independent group of medical students motivated by experiences in their scientific associations, established the first student-led, peer-reviewed journal to share the scientific production and experiences of medical students worldwide. ${ }^{63}$ In addition, these leadership and research experiences uniquely equip students to become the future leaders of medicine and public health, whether as successfully funded investigators, coordinators of multinational clinical trials, or representatives at the forefront of global health projects, catalysts for public health reforms, or other envoys to serve society.

For medical students, excellence comes from doing more in life than just fulfilling the requirements of a curriculum. The intangible and most commonly overlooked experiences are as valuable as those quantified by papers and presentations. A systematic review showed that participation in leadership training programs had positive effects on faculty advancement in academic rank and success in publishing papers. ${ }^{64}$ Thus, similar effects have the potential to be realized among medical students participating in early leadership research positions, providing a jumpstart to exercising these roles in their future professional careers.

\section{Elevating Medical Students to the Demand of Current Medicine}

Although research is central to the practice of EBM, the AAMC has identified physician-scientists as a "vulnerable population" because of their declining number and higher rates of failure to achieve funding when compared to non-physician investigators. ${ }^{45}$ Despite the numerous insights into the molecular biology and pathophysiology of diseases made in the past few decades, much of this knowledge has yet to be applied to clinical practice and public health. ${ }^{65}$ of 101 studies published in six major basic science journals that reported their discovery had novel therapeutic or preventive promise, only five had been licensed for clinical use. ${ }^{65}$ The lack of clinical and translational investigators and a less-than-ideal cooperative communication between basic scientists and clinical investigators were reported as significant barriers to the translation of research. ${ }^{65}$ Physician-scientists are uniquely qualified to make discoveries by bringing together experimental data from the bench with clinical observations. ${ }^{43}$

To answer these demands, several strategies have been implemented. The AAMC, the NIH, and several non-profit institutions have designed programs to revitalize the physician-scientist pathway. ${ }^{35,45,66,67}$ Medical schools offer joint MD-PhD programs or incorporate scholarly research programs to emphasize disciplined research activities in their students. ${ }^{27,46,54,68}$ Residency and fellowship programs have established research-oriented tracks to train physician-scientists and achieve both their clinical and 


\section{Review}

research goals during their training in an attempt to reduce the time to becoming independent investigators. ${ }^{51,53,69}$ Therefore, it is important that research, in either a direct or indirect manner, effectively enters into physicians' thoughts to become truly integrated into their lifelong career and is not perceived simply as a fleeting obligation.

In addition, research fulfills a social goal by producing new knowledge to offer better care. This is evident in developed countries where pioneering treatments are conceived and tested. However, there are still many challenges to be addressed at local, national, and international levels, which require solutions from both a clinical and public health perspective. Current global health issues include the rising burden of non-communicable diseases, the effects of climate change, and trade policies. These new burdens are an addition to the unresolved problems of infections, malnutrition, and reproductive health, which continue to evolve in a dynamic and complex global context. ${ }^{\circ}$ Also, the increasing migration of physicians and patients in a world healthcare market makes these challenges more interlinked and interdependent than before, requiring innovative approaches that should include strategies in medical education and healthcare delivery. ${ }^{71}$ By promoting more meaningful participation in research initiatives among medical students from all continents, the next generation of physicians, scientists and leaders can continue to develop innovative strategies for management of diseases through international collaboration that address the health problems of people of all nations, both in developed and developing countries. Thus, participation in research promotes a higher perception about the value of personal accomplishment and the rewarding feeling of contributing not only to one's own community but to many others in need. ${ }^{12}$

\section{Concluding Remarks}

The majority of first-year medical students may reiterate that their primary reason to enter medicine is to help people and their communities. This concept no longer lies solely in the altruistic doctor who sets off in a romantic adventure to serve society. Instead, the responsibility to address health issues that our communities face and play an active role in their solution lies with all physicians (current and future). While this happens every day in clinical practice, is it enough? As future leaders in medicine, is it not the responsibility of physicians-in-training to do more? It is your turn as a medical student embrace the breakthroughs in medicine and take them to the next level, address the challenges, and "advance in the pathway of creating knowledge to enhance the health of our communities and nations"..$^{2}$ 


\section{References}

1. Evidence-Based Medicine Working G. Evidence-based medicine. A new approach to teaching the practice of medicine. JAMA : the journal of the American Medical Association 1992;268:2420-5.

2. Burazeri G, Civljak M, Ilakovac V, et al. Survey of attitudes and knowledge about science in medical students in southeast Europe. Bmj 2005;331:195-6.

3. Vodopivec I, Vujaklija A, Hrabak M, Lukic IK, Marusic A, Marusic $M$. Knowledge about and attitude towards science of first year medical students. Croatian medical journal 2002;43:58-62. 4. Shankar PR, Dubey AK, Upadhyay DK, Subish P, Mishra P. Science attitudes and knowledge among preclinical medical students in Pokhara, Nepal. Collegium antropologicum 2007;31:667-73.

5. Khan H, Khawaja MR, Waheed A, Rauf MA, Fatmi Z. Knowledge and attitudes about health research amongst a group of Pakistani medical students. BMC medical education 2006;6:54. 6. Wyngaarden JB. The clinical investigator as an endangered species. The New England journal of medicine 1979;301:1254-9. 7. Miller ED. Clinical investigators--the endangered species revisited. JAMA : the journal of the American Medical Association 2001;286:845-6.

8. Sinclair S. Evidence-based medicine: a new ritual in medical teaching. British medical bulletin 2004;69:179-96.

9. Poynter FNL, Keele KD. A short history of medicine. London,: Mills at Boon; 1961.

10. Ludmerer KM. Commentary: Understanding the Flexner report. Academic medicine : journal of the Association of American Medical Colleges 2010;85:193-6.

11. Teo AR. The development of clinical research training: past history and current trends in the United States. Academic medicine : journal of the Association of American Medical Colleges 2009;84:433-8

12. Nayak BK. Why learn research methodology? Indian journal of ophthalmology 2009;57:173-4.

13. Elstein AS. On the origins and development of evidence-based medicine and medical decision making. Inflammation research : official journal of the European Histamine Research Society [et al] 2004;53 Suppl 2:S184-9.

14. Flexner A. Medical Education in the United States and Canada: A Report to the Carnegie Foundation for the Advancement of Teaching. Bulletin No 4 Boston, Mass: Updyke 1910.

15. WFME task force on defining international standards in basic medical education. Report of the working party, Copenhagen, 14-16 October 1999. Medical education 2000;34:665-75. 16. Rosenkranz SK, Wang S, Hu W. Motivating medical students to do research: a mixed methods study using Self-Determination Theory. BMC medical education 2015;15:95.

17. Rose SH, Long TR, Elliott BA, Brown MJ. A historical perspective on resident evaluation, the Accreditation Council for Graduate Medical Education Outcome Project and Accreditation Council for Graduate Medical Education duty hour requirement. Anesthesia and analgesia 2009;109:190-3.

18. Devi V, Ramnarayan K, Abraham RR, Pallath V, Kamath A, Kodidela S. Short-term outcomes of a program developed to inculcate research essentials in undergraduate medical students. J Postgrad Med 2015;61:163-8.

19. Sheikh AS, Sheikh SA, Kaleem A, Waqas A. Factors contributing to lack of interest in research among medical students. Advances in medical education and practice 2013;4:237-43.
20. Burgoyne LN, O'Flynn S, Boylan CB. Undergraduate medical research: the student perspective. Medical education online 2010;15.

21. Siemens DR, Punnen S, Wong J, Kanji N. A survey on the attitudes towards research in medical school. BMC medical education 2010;10:4.

22. Chang Y, Ramnanan CJ. A review of literature on medical students and scholarly research: experiences, attitudes, and outcomes. Academic medicine : journal of the Association of American Medical Colleges 2015;90:1162-73.

23. Memarpour M, Fard AP, Chasemi R. Evaluation of attitude to, knowledge of and barriers toward research among medical science students. Asia Pac Fam Med 2015;14:1.

24. Park SJ, McChee CN, Sherwin T. Medical students' attitudes towards research and a career in research: an Auckland, New Zealand study. The New Zealand medical journal 2010;123:3442.

25. Jacobs CD, Cross PC. The value of medical student research: the experience at Stanford University School of Medicine. Medical education 1995;29:342-6.

26. Naing C, Wai VN, Durham J, et al. A Systematic Review and Meta-Analysis of Medical Students' Perspectives on the Engagement in Research. Medicine (Baltimore) 2015;94:e1089.

27. Laskowitz DT, Drucker RP, Parsonnet J, Cross PC, Cesundheit $N$. Engaging students in dedicated research and scholarship during medical school: the long-term experiences at Duke and Stanford. Academic medicine : journal of the Association of American Medical Colleges 2010;85:419-28.

28. Wilkerson L, Abelmann WH. Producing physician-scientists: a survey of graduates from the Harvard--MIT Program in Health Sciences and Technology. Academic medicine : journal of the Association of American Medical Colleges 1993;68:214-8.

29. Abelmann WH, Nave BD, Wilkerson L. Generation of physician-scientists manpower: a follow-up study of the first 294 graduates of the Harvard-MIT Program of Health Sciences and Technology. Journal of investigative medicine : the official publication of the American Federation for Clinical Research 1997:45:272-5.

30. Rosenblatt RA, Desnick L, Corrigan C, Keerbs A. The evolution of a required research program for medical students at the University of Washington School of Medicine. Academic medicine : journal of the Association of American Medical Colleges 2006;81:877-81.

31. Frishman WH. Student research projects and theses: should they be a requirement for medical school graduation? Heart Dis 2001;3:140-4.

32. Kuhnigk 0, Bothern AM, Reimer J, et al. Benefits and pitfalls of scientific research during undergraduate medical education. GMS Zeitschrift fur medizinische Ausbildung 2010;27:Doc72.

33. Solomon SS, Tom SC, Pichert J, Wasserman D, Powers AC. Impact of medical student research in the development of physician-scientists. Journal of investigative medicine : the official publication of the American Federation for Clinical Research 2003;51:149-56.

34. Ogunyemi D, Bazargan $M$, Norris $K$, et al. The development of a mandatory medical thesis in an urban medical school. Teaching and learning in medicine 2005;17:363-9.

35. Ley TJ, Rosenberg LE. The physician-scientist career pipeline in 2005: build it, and they will come. JAMA : the journal of the American Medical Association 2005;294:1343-51.

36. Kulasegaram KM, Martimianakis MA, Mylopoulos M, White- 
head CR, Woods NN. Cognition Before Curriculum: Rethinking the Integration of Basic Science and Clinical Learning. Academic medicine : journal of the Association of American Medical Colleges 2013.

37. De Avila P, Jr., Torres BB. Introducing undergraduate students to science. Biochemistry and molecular biology education : a bimonthly publication of the International Union of Biochemistry and Molecular Biology 2010;38:70-8.

38. Nazha B, Salloum RH, Fahed AC, Nabulsi M. Students' perceptions of peer-organized extra-curricular research course during medical school: a qualitative study. PLoS One 2015;10:e0119375. 39. Ozuah PO. Residency research requirement as a predictor of future publication productivity. The Journal of pediatrics 2009;155:1-2, e1.

40. Bettmann M. Choosing a research project and a research mentor. Circulation 2009;119:1832-5.

41. Mireles-Cabodevila E, Stoller JK. Research during fellowship: ten commandments. Chest 2009;135:1395-9.

42. Packer CD, Katz RB, lacopetti CL, Krimmel JD, singh MK. A Case Suspended in Time: The Educational Value of Case Reports. Academic medicine : journal of the Association of American Medical Colleges 2016.

43. Brown NJ. Developing physician-scientists: a perspective. Transactions of the American Clinical and Climatological Association 2013;124:218-29.

44. Thakur A, Thakur V, Fonkalsrud EW, Singh S, Buchmiller TL. The outcome of research training during surgical residency. The Journal of surgical research 2000;90:10-2.

45. Dickler HB, Korn D, Gabbe SG. Promoting translational and clinical science: the critical role of medical schools and teaching hospitals. PLoS medicine 2006;3:e378.

46. Mendicino RW, Catanzariti AR. Residencies and publications. The Journal of foot and ankle surgery : official publication of the American College of Foot and Ankle Surgeons 2009;48:101-2. 47. Houlden RL, Raja JB, Collier CP, Clark AF, Waugh JM. Medical students' perceptions of an undergraduate research elective. Medical teacher 2004;26:659-61.

48. Vujaklija A, Hren D, Sambunjak D, et al. Can teaching research methodology influence students' attitude toward science? Cohort study and nonrandomized trial in a single medical school. Journal of investigative medicine : the official publication of the American Federation for Clinical Research 2010;58:282-6.

49. Straus SE, Straus C, Tzanetos K. Career choice in academic medicine: systematic review. Journal of general internal medicine 2006;21:1222-9.

50. Fang D, Meyer RE. Effect of two Howard Hughes Medical Institute research training programs for medical students on the likelihood of pursuing research careers. Academic medicine : journal of the Association of American Medical Colleges 2003;78:1271-80.

51. Kapoor K, Wu BU, Banks PA. The value of formal clinical research training in initiating a career as a clinical investigator. Gastroenterology it hepatology 2011;7:810-3.

52. Dicianno BE, Glick RM, Sowa GA, Boninger ML. Processes and Outcomes from a Medical Student Research Training Program in Integrative, Complementary, and Alternative Medicine. Am J Phys Med Rehabil 2016.

53. Arbuckle MR, Gordon JA, Pincus HA, Oquendo MA. Bridging the gap: supporting translational research careers through an integrated research track within residency training. Academic medicine : journal of the Association of American Medical Colleges 2013;88:759-65.

54. Andriole DA, Jeffe DB, Hageman $\mathrm{HL}$, et al. Variables associated with full-time faculty appointment among contemporary U.S. Medical school graduates: implications for academic medicine workforce diversity. Academic medicine : journal of the Association of American Medical Colleges 2010;85:1250-7.

55. Buddeberg-Fischer B, Stamm M, Buddeberg C. Academic career in medicine: requirements and conditions for successful advancement in Switzerland. BMC health services research 2009;9:70.

56. O'Sullivan PS, Niehaus B, Lockspeiser TM, Irby DM. Becoming an academic doctor: perceptions of scholarly careers. Medical education 2009;43:335-41.

57. Goldhamer ME, Cohen AP, Bates DW, et al. Protecting an endangered species: training physicians to conduct clinical research. Academic medicine : journal of the Association of American Medical Colleges 2009;84:439-45.

58. Lessin MS, Klein MD. Does research during general surgery residency correlate with academic pursuits after pediatric surgery residency? Journal of pediatric surgery 1995;30:1310-3.

59. Jeffe DB, Yan Y, Andriole DA. Do research activities during college, medical school, and residency mediate racial/ethnic disparities in full-time faculty appointments at U.S. Medical schools? Academic medicine : journal of the Association of American Medical Colleges 2012;87:1582-93.

60. Green M, Jones P, Thomas JX, Jr. Selection criteria for residency: results of a national program directors survey. Academic medicine : journal of the Association of American Medical Colleges 2009;84:362-7.

61. Rogers CR, Gutowski KA, Munoz-Del Rio A, et al. Integrated plastic surgery residency applicant survey: characteristics of successful applicants and feedback about the interview process. Plastic and reconstructive surgery 2009;123:1607-17.

62. Bonilla-Escobar F], Bonilla-Velez ], Lopez-Castillo C. [Medical Student Research: Perspective from Colombia]. CIMEL 2010;15. 63. Bonilla-Velez J, Peña-0scuvilca A, Sahin I, Córdoba-Grueso W, Fernandez-Zapico M. The International Journal of Medical Students, a Platform for Medical Student Research Worldwide. Int J Med Students 2013;1:6-7.

64. Straus SE, Soobiah C, Levinson W. The impact of leadership training programs on physicians in academic medical centers: $a$ systematic review. Academic medicine : journal of the Association of American Medical Colleges 2013;88:710-23.

65. Contopoulos-Ioannidis DG, Ntzani E, Ioannidis JP. Translation of highly promising basic science research into clinical applications. The American journal of medicine 2003;114:477-84.

66. Heller C, de Melo-Martin I. Clinical and Translational Science Awards: can they increase the efficiency and speed of clinical and translational research? Academic medicine : journal of the Association of American Medical Colleges 2009;84:424-32.

67. Switzer GE, Robinson GF, Rubio DM, Fowler NR, Kapoor WN. Doctoral Programs to Train Future Leaders in Clinical and Translational Science. Academic medicine : journal of the Association of American Medical Colleges 2013;88:1332-9.

68. Jeffe DB, Andriole DA. A national cohort study of MD-PhD graduates of medical schools with and without funding from the National Institute of Ceneral Medical Sciences' Medical Scientist Training Program. Academic medicine : journal of the Association of American Medical Colleges 2011;86:953-61.

69. Brass LF, Akabas MH, Burnley LD, Engman DM, Wiley CA, 
Andersen OS. Are MD-PhD programs meeting their goals? An analysis of career choices made by graduates of $24 \mathrm{MD}-\mathrm{PhD}$ programs. Academic medicine : journal of the Association of American Medical Colleges 2010;85:692-701.

70. Frenk J, Moon S. Governance challenges in global health. The New England journal of medicine 2013;368:936-42.

71. Crisp N, Chen L. Global supply of health professionals. The New England journal of medicine 2014;370:950-7.

72. Pincus HA. Challenges and pathways for clinical and translational research: why is this research different from all other research? Academic medicine : journal of the Association of American Medical Colleges 2009;84:411-2.

\section{Acknowledgment}

The authors would like to thank Stuart Mires and Dana Shaw-Bailey for their help in revising the manuscript, as well as ACEMVAL, ASCEMCOL, FELSOCEM, IFMSA and IJMS for providing spaces and opportunities for medical students to excel, to grow and to contribute to their societies and to the progress of medicine worldwide.

\section{Conflict of Interest Statement at Funding}

This work was supported, in part, by funding from the Fraternal Order of Eagles and a Career Development Award from the Mayo Clinic SPORE in Pancreatic Cancer (P50 CA102701, both to CL), the National Institutes of Health (grant DK52913 to RU), the Mayo Clinic Center for Cell Signaling in Gastroenterology (P30DK084567), and the Mayo Foundation. The authors report no conflict of interest.

\section{Author Contributions}

Conception and design the work/idea, write the manuscript: $\mathrm{GL}$, JBV, RU. Critical revision of the manuscript, approval of the final version: $\mathrm{GL}, \mathrm{JBV}, \mathrm{RU}, \mathrm{MS}$. Obtaining Financing: GL, RU, MS. Administrative of technical advice: GL, JBV, RU, MS.

Cite as:

Bonilla-Velez J, Small M, Urrutia R, Lomberk G. The Enduring Value of Research in Medical Education. Int J Med Students. 2017 Jan-Apr;5(1): $37-44$. 